\title{
Chosen Aspects of Packages in the Distribution of Selected Dairy Products
}

\author{
Jacek Caban $^{1 *}$ and Kateryna Kravchenko ${ }^{2}$ \\ ${ }^{1}$ University of Life Science in Lublin, Faculty of Production Engineering, Gtęboka Street 28, 20-612 \\ Lublin, Poland;Email: jacek.caban@up.lublin.pl \\ ${ }^{2}$ Volodymyr Dahl East Ukrainian National University, Faculty of Transport and Logistics, Central \\ Avenue 59a, 93-400 Severodonetsk, Ukraine; Email: kkatherina@ukr.net
}

\section{*Corresponding Author: Jacek Caban}

\begin{abstract}
Distribution of dairy products is one of the most important activities in the production process deciding about the organization of production and the course of technological processes. Such products should be provided with suitable containers with protective coatings, maintain the appropriate temperature during transport, and most importantly, the sterility of the means of transport. Choosing the right packaging for perishable products is not an easy matter, as it has to fulfil many functions. The article presents some aspects of the packaging system and legal conditions for the distribution of selected dairy products. In the first chapter, short introduction for the issue of packaging market of dairy products is presented. Second chapter outlines the selected legal acts regarding food transport in Poland. Selected aspects in terms of choosing the type of packaging and used materials are described in chapter 3. The last chapter contains conclusions and final remarks for the distribution of selected dairy products.
\end{abstract}

Keywords: Logistic chain, packages, transport, product safety

\section{Introduction}

Transport plays a very important role in human life and makes it easier in many areas of life. Ensuring the safe transport of dairy products with a short shelf life requires appropriate conditions of carriage and packaging. Food products are unstable, since they contain features of living organisms, through the influence of such factors as: air, temperature, humidity, microorganisms, light, cleanliness of rooms, and even storage time affect faster conversion of biochemical, microbiological or physical processes. In addition, the stages of production and distribution of such products must be adapted to their nature so as to avoid negative environmental factors affecting its quality. The issue of food supply chain quality and risk has received significant attention in recent years, especially in emerging markets [1]. The fulfilment of these criteria is a big challenge for the implementation of the distribution process of such products. Droździel et al. [2] wrote about 
problems associated with distribution in a logistics centre working in a given area of the Lubelskie Voivodship.

Dairy products must reach the recipient without any quality damage and most importantly - they must not endanger human health. Therefore, to ensure the proper transport chain of these items, the temperature, humidity and transport time should be adjusted, appropriate transport means and appropriate personnel should be selected to service the load, including drivers. The increased public awareness regarding food safety has impelled the dairy industry to improve the safety and image of dairy products $[3,4]$.

In the dairy industry, as in the entire agro-food industry, in recent years there has been an intense development of production techniques and technologies [5], which resulted in a variety of products offered, but also much more demanding for the distribution process. Company owners must face the challenges of the market, such as: globalisation, increasing competition, rapid introduction of new technologies, not to mention growing consciousness of consumers, who demand better quality products and services [6,7]. This means manufacturers must act more timeand cost-effectively [8-10]. To ensure the proper way of transport service, we have various transport systems at our disposal. The specificity of the dairy industry makes its products are mainly transported by road means of transport. As a result, packaging of perishable goods may be regarded only as a part of the entire logistics system [11].

The article presents selected aspects of the packaging system used to pack dairy products. Technical conditions and legal acts regulating the transport of this type of products are presented. In addition, the most popular types of packaging were presented using the following groups of materials: glass, plastic, cardboard and aluminium foil.

\section{Selected Legal Acts Regarding Food Transport in Poland}

The transport of food products, which includes fresh, dry, loose, liquid, frozen and solid products, is subject to strict legal regulations. ATP (formally, the Agreement on the International Carriage of Perishable Foodstuffs and on the Special Equipment to be used for such Carriage [12]) is the treaty that establishes standards for the international transport of perishable food. To maintain the appropriate conditions of transport, each vehicle must meet certain thermal insulation conditions, and the cooling unit should maintain the temperature in the cargo area at the level corresponding to the specificity of the transported goods.

Means of transport intended for transporting yoghurts and kefirs must maintain a constant temperature of $4{ }^{\circ} \mathrm{C}$ and the transport time should not exceed 48 hours. When transporting butter, the temperature should be maintained at $5{ }^{\circ} \mathrm{C}$. Such conditions help to maintain the correct quality, 
health and taste of perishable goods from loading to unloading time and provides the consumer with proper freshness. In domestic transport, where the transport time is relatively short, this is not a problem, but it is of great importance for international transport. If the carrier transports a food load which is subject to the contract, he must have a certificate or copy of ATP, which authorizes him to transport food outside the state borders and at the same time confirms the fulfilment of the requirements for the vehicle. In the case of transport inspections, control authorities have the right and the opportunity to inspect this contract during the inspection.

In addition, both the production plant (cooperative) and the carrier are required to implement the HACCP (Hazard Analysis and Critical Control Points) system in the plant. It has been developed to identify and control hazards that may arise at various stages of food production and distribution. The use of the HACCP system enables detection of threats and their elimination to a much greater extent than traditional methods (checking of selected product batches), where the probability of detecting an epidemic is only about $1 \%$.

The carrier must comply with a number of legal requirements, which they include:

- Regulation of the Minister of Health of December 19, 2002 (Journal of Laws No. 234, item 1979) on the hygiene and sanitary requirements of plants and hygiene requirements in the production process and in trade in articles and materials and articles intended for contact with these products,

- Regulation No 853/2004 of the European Parliament and of the Council of 29 April 2004 laying down specific hygiene rules for food of animal origin,

- Act of 25 August 2006 on food and nutrition safety,

- Regulation No. 178/2002 of the European Parliament and of the Council of 28 January 2002, laying down the general principles and requirements of food law, establishing the European Food Safety Authority and laying down procedures on food security,

- Certificate from the competent Veterinary Inspection and / or Poviat Sanitary Inspectorate. The entrepreneur is required to obtain a veterinary number that enables him to carry out activities related to the logistics chain for the supply of animal products. This has been included in the requirements of the provisions of the Act on animal products (EC) No. $853 / 2004$,

- Convention on the Contract for the International Carriage of Goods by Road (CMR), dated 19 May 1956, drawn up in Geneva. 


\section{Selected Aspects of Choosing the Type of Packaging}

Depending on the functions performed, we can divide the packaging into:

- unit packages, whose task is to collect individual pieces of a product or its portions. They protect products against quantitative losses and also partly against qualitative changes,

- -collective packaging, they combine a fixed number of pieces of product or unit packages into a larger whole,

- transport packaging, they are packaging that facilitates transport and storage. Their task is to protect the contents of the packaging against climatic and biological factors as well as mechanical damage during the storage and transport process. [13].

Packaging is a physical form of product protection against changes during its movement, storage and use. Another function of the packaging is to provide information about the product and its producer and the psychological impact on the consumer. The aesthetics of the packaging encourages you to buy a given article and attracts attention on the store shelf. The packaging should be adapted to the properties of individual goods. The essence of packaging is, therefore, the appropriate selection of materials, so that they can best protect the goods from the harmful effects of external factors and preserve the properties of the product. Given the huge variety of food products, as well as the constantly increasing range of packaging materials, the appropriate selection of packaging for the protected product is extremely important, but also complex [14]. According to the PIO (Polish Chamber of Packaging) report, in 2013 the largest market share was occupied by food and beverage packaging - $64.8 \%$, followed by packaging of industrial goods and household chemicals $-22.2 \%$, further by drug packaging $-7.0 \%$ and packaging for cosmetics and personal care $-6.0 \%$.

In the technological process, the consistency of the product plays an important role in the selection of the optimal packaging method. It can be in liquid form, such as fermented milk, semiliquid as yogurt and solid in the form of butter. The packaging should indicate the shelf life of the product. For example, the expiry date of yogurts and kefirs ranges from $3 \div 4$ days to 3 months. These products undergo constant chemical changes, e.g. fat rancidity, decomposition of vitamins, etc., as well as physical processes, e.g. evaporation or absorption of water. Therefore, the choice of packaging should take into account the specificity of milk products. Selected dairy products are stored and transported under refrigeration conditions. Therefore, the packaging material has to retain its properties over a wider temperature range.

Milk fermented beverages are packed into the following forms:

- glass bottles or jars,

- plastic bottles with a capacity of $250 \mathrm{~cm}^{3}$, 
- cups pressed from foil PS or PP closed with aluminium foil,

- multilayer cardboard packaging with a capacity of 200 to $1000 \mathrm{~cm}^{3}$.

Transport of food products requires specially selected protection. It is necessary to ensure properly selected containers with appropriate protective coatings, maintain the right temperature during transport and, most importantly, ensure the sterility of the means of transport. Protective coatings should be selected so that they do not react with the product and additionally maximally insulate the finished product from the influence of the environment.

\section{1. $\quad$ Glass Packaging}

Glass packaging is characterized by the fact that their coating is an impermeable barrier between the product and the environment. The glass is characterized by high resistance to all atmospheric influences and chemical substances. The great advantage of glass packaging is the ease in their production and moulding, and thanks to the rigid construction they retain the original shape throughout the entire period of use. In the dairy industry, glass products are increasingly used, such as jars, into which yogurt is poured. These jars are not only resistant to external and internal factors, but also very aesthetic [15]. The disadvantage of this type of packaging is its higher unit weight compared to other packaging materials.

\subsection{Packaging Made of PS and PP Film}

The most commonly used packaging for fermented beverages are cups pressed from PS and PP foil. Currently, there is a tendency to replace paper and glass with plastic packaging. Their special features are physical and chemical properties, such as: good mechanical strength, low specific gravity, ease of forming and bonding, high barrier to penetration of gases and water, as well as high resistance to chemical agents. Plastic packaging is also characterized by the possibility of combining them with other packaging materials [16]. Plastic packaging is marked with the appropriate symbols shown in Figure 1.

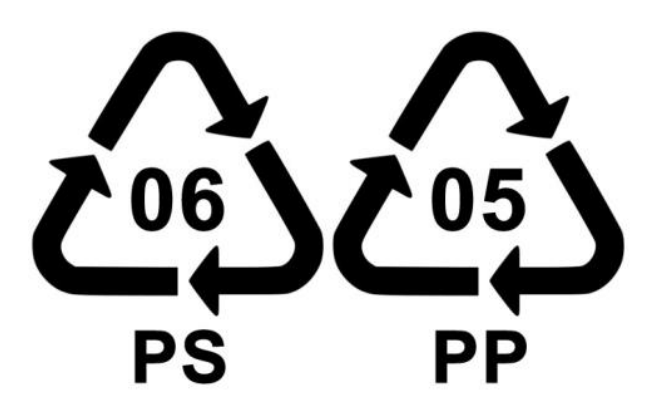

Fig. 1 Marking of products made of polystyrene (PS) and polypropylene (PP). Source: [17] 
Polystyrene (PS) is a transparent plastic resistant to acid, water and alkaline and easy to dye. Used mainly for the production of disposable cups and cups for storing yogurts [16], or for cottage cheese and cheese for children.

Polypropylene (PP) is formed by injection or extrusion, it is characterized by high resistance to high temperatures and water. Polypropylene does not react with bases, acids and water. Packages made of PP in comparison with PS have better mechanical properties, it is also one of the safer plastics for the natural environment, due to the fact that the packaging made from it is fully recyclable.

\subsection{Cardboard Packaging}

The most popular material used for making bulk packaging is cardboard. Its basic advantages include: low price, low specific weight, good mechanical properties, ease of printing and, above all, that it is made of biodegradable, natural, renewable and reprocess able plant fibbers. However, main disadvantages of paper products, include very high water absorption, permeability of fat and gases, as well as low possibilities of joining paper materials. However, these defects are now eliminated by the use of coating and laminating paper packaging [16]. Examples of various products and shapes of packaging made of cardboard, and used, inter alia, in the agro-food industry are shown in Figure 2.

a)

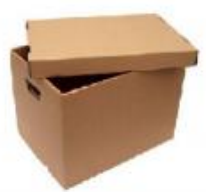

c)

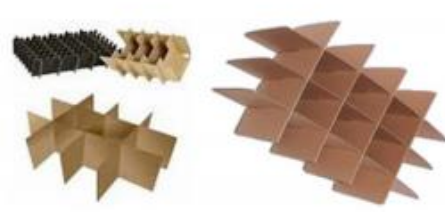

b)

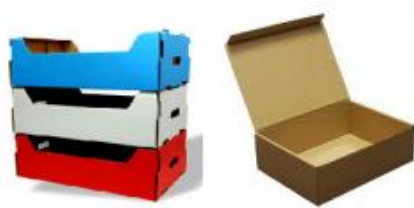

d)
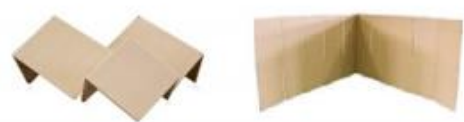

e)

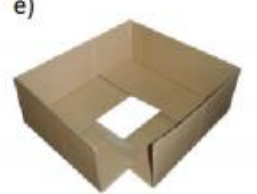

a) slotted-type box, b) die-cut box, c) lattice, d) divider, e) sleeve.

Fig. 2 Examples of different cardboard packaging. Source: [17]

Strengthening cardboard depends on the type of packaging, its function and application. On the market, we can distinguish solid cardboard, which usually constitutes the top coloured layer and corrugated cardboard responsible for the durability of the packaging. Cardboard packaging can be 
made in the form of corrugated board: two-, three-, five- and seven-layer. Cardboard packaging is used for confectioning products and as a multipack for individual items (butter, yogurt, milk, etc.). It should be added that multilayer packaging can exist as so-called aseptic carton for packaging products with extended shelf-life and non-aseptic carton - intended for packaging of short-term products. The aseptic carton consists of about $70 \%$ paper, polyethylene about $20 \%$ and aluminium foil up to about $10 \%$.

\subsection{Paper and Aluminium Foil Packaging}

In some cases, more than one type of material should be used. This is the case with the packaging of butter, where its unit packaging is parchment paper with imprint or aluminium foil integrated with parchment paper (see Fig. 3). A better solution is the latter, because the aluminium foil better protects the article from the harmful effects of sunlight, rancidity or drying. When selecting packaging for butter, we can also distinguish aluminium foil with a thickness of $0.009 \mathrm{~mm}$, coated on both sides and laminated with ceiling paper [16]. This solution provides even better protection, while it is less frequently used in Polish dairy plants. Perhaps in the future, the share of the latter material as a packet of butter will be larger. Another solution used for packaging butter is made of polypropylene.

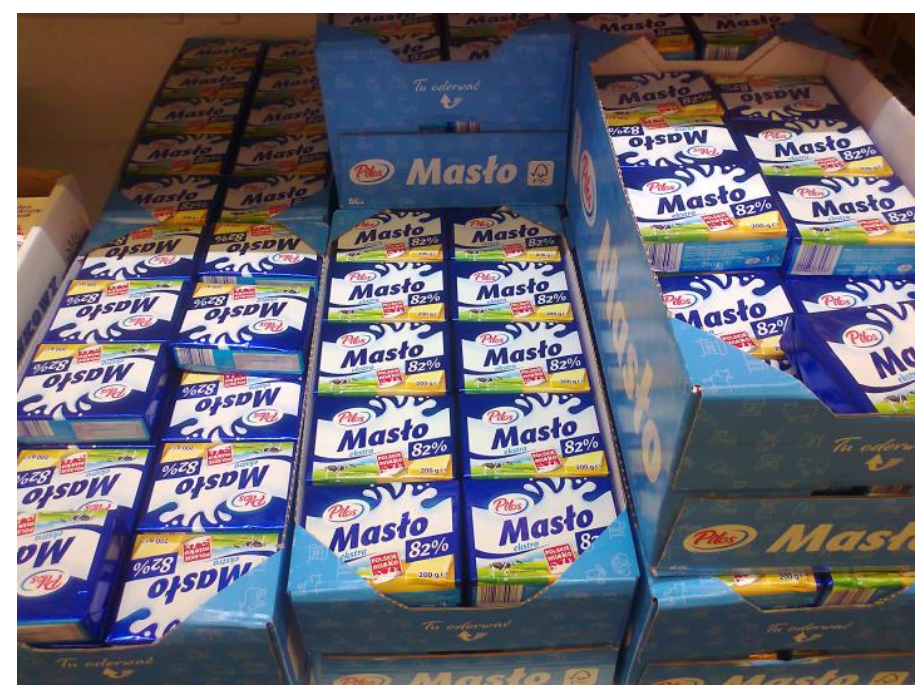

Fig. 3 Example of butter in a cardboard collective packaging. Source: author

\section{Conclusion}

In conclusion, it should be noted that the food industry uses, among others, multi-layer cardboard packaging, cardboard and paper packaging, plastic-coated paper packaging, plastic packaging (PET, LDPE, HDPE, PS and PP), and glass and metal packaging. Plastics, like cardboard, are one of the most commonly used packaging materials in the dairy industry, displacing glass materials. Milk and 
fermented beverages (e.g. kefir) are currently packaged in two types of packaging. The first group consists of plastic packaging, and the second is a variety of cartons composed of several layers of different construction materials (like cardboard, aluminium foil). Some manufacturers return back to glass packaging for yogurt though.

Among plastic bottles, different types of PET bottles, LDPE containers and HDPE bottles (with a thick carbon layer) covered with double layer foil may be indicated. In the case of plastic packaging, great care is advised when selecting them due to the toxicity problem for the human body. It is conditioned by the possibility of migration of harmful compounds from the packaging to the product (e.g. BPA, i.e. bisphenol A). Another problem is the threat to the natural environment resulting from the long and difficult decomposition of used plastic packaging. In order to reduce the consumption of plastic packaging, there have recently been additional fees for bags and plastic bags at points of sale. In addition, materials and articles intended for contact with food must be accompanied by a declaration of compliance [17].

The distribution of dairy products is one of the most important links in the production process, as it determines the organization of production, the course of technological processes as well as affects the quality and safety of finished products and their transport. Among the huge selection of packaging materials, care should be taken that the packaging ensures proper product safety, protects it against environmental factors and does not change the quality of the packed product. Analysing the selection of the right packaging for fermented products, the glass has the greatest number of advantages, but it is not so often used, because it is much more exposed to mechanical damage during transport and has a higher specific gravity than e.g. plastics.

\section{References}

[1] Chen, C., Zhang, J. \& Delaurentis, T. (2014). Quality control in food supply chain management: an analytical model and case study of the adulterated milk incident in China. Int. J. Prod. Econ. 152 (6), 188-199.

[2] Droździel, P., Wińska, M., Madlenak, R. \& Szumski, P. (2017). Optimization of the post logistics network and location of the local distribution center in selected area of the Lublin province. In $12^{\text {th }}$ International Scientific Conference of Young Scientists on Sustainable, Modern and Safe Transport, Procedia Engineering, 31 May - 02 Jun 2017 (pp. 130-135). Amsterdam, Netherlands: ELSEVIER SCIENCE BV.

[3] Pant, R.R., Prakash, G. \& Farooquie, J.A. (2015). A framework for traceability and transparency in the dairy supply chain networks. In Procedia Soc. Behav. Sci, 12-14 December 2014 (pp. 385-394). Amsterdam, Netherlands: ELSEVIER SCIENCE BV. 
[4] Valeeva, N.I., Huirne, R.B.M., Meuwissen, M.P.M. \& Lansink, A.G.J.M.O. (2007). Modeling farm-level strategies for improving food safety in the dairy chain. Agric. Syst. 94 (2), 528-540.

[5] Pawlak, H., Jasiński, K., Pecyna, A. \& Pecyna, M. (2012). Ergonomiczna ocena warunków pracy na stanowiskach pakowania mleka. Agricultural Engineering nr. 3(138), 185-191.

[6] Relich, M. (2013). Fuzzy project scheduling using constraint programming. Applied Computer Science. 9 (1), 3-16.

[7] Shah, R. \& Ward, P.T. (2007). Defining and developing measures of Lean Production. Journal of Operations Management. 25 (4), 785-805.

[8] Bocewicz, G., Nielsen, I. \& Banaszak, Z. (2014). Iterative multimodal process scheduling. Annual Reviews in Control. 38 (1), 113-132.

[9] Lizbetin, J. \& Stopka, O. (2016). Practical application of the methodology for determining the performance of a combined transport terminal. In 3rd International Conference on Traffic and Transport Engineering (ICTTE), 24-25 November 2016 (pp. 382-387). Belgrade, Serbia: Scientific Research Center LTD Belgrade.

[10] Sobaszek, Ł. \& Gola, A. (2015). Computer-aided production task scheduling. Applied Computer Science. 11 (4), 58-69.

[11] Patlins, P. (2016). Efficient transportation in cities and perishable goods secondary packaging. In $15^{\text {th }}$ International Scientific Conference, Engineering for Rural Development, 25-27 May 2016 (pp. 1395-1401). Jelgava, Latvia: LATVIA UNIV AGRICULTURE.

[12] Piekarski, W. \& Maj, G. (2013). Środki transportu, tom I. Lublin, Poland: Towarzystwo Wydawnictwo Naukowych LIBROPOLIS.

[13] Jakowski, S. (2007). Opakowania transportowe. Warszawa, Poland: poradnik. WNT.

[14] Sumińska, P. \& Dmytrów, I. (2015). Opakowania do produktów mlecznych. Przemysł Spożywczy nr. 10, 38-42.

[15] Panfil-Kuncewicz, H., Juśkiewicz, M. \& Kuncewicz, A. (1997). Opakowania i Transport w Mleczarstwie. Poland: ART Olsztyn.

[16] Rudawska, A., Čuboňova, N., Pomarańska, K., Stančeková, D. \& Gola, A. (2016). Technical and organizational improvements of packaging production process. Advances in Science and Technology Research Journal. 10 (30), 182-192.

[17] Pawlicka, M. (2017). Kontakt tylko z deklaracją. Kierunek Spożywczy nr. 4, 18-20. 